\title{
Juventude(s) e ensino médio: relação dos estudantes com a escola e com o saber em territórios de vulnerabilidade social $^{1}$
}

Pâmela Félix Freitas* Antônio Augusto Gomes Batista** Hivy Damasio Araújo Mello***

$\begin{array}{lrrr}* \text { (Cenpec, } & \text { São } & \text { Paulo, } & \text { SP }) \\ * *(\text { Cenpec, } & \text { São } & \text { Paulo, } & \text { SP }) \\ * * *(\text { Cenpec, } & \text { São } & \text { Paulo, } & \text { SP })\end{array}$

Resumo: O objetivo deste artigo é contribuir para uma maior compreensão e enfrentamento dos problemas e desafios encontrados pelos jovens na sua relação com a escola e com o saber, em particular em territórios mais vulneráveis. Analisou-se um questionário aplicado a 669 estudantes da $2^{a}$ série do ensino médio de 24 escolas estaduais em 17 municípios do Ceará, Goiás, Pernambuco e São Paulo. Foram identificadas diferenças entre o perfil dos alunos dos períodos parcial e integral e como as condições escolares - e a diferenciação das oportunidades educacionais tendem a afetar e conformar a relação dos jovens com a própria a escola e com o saber, bem como o modo como eles encaram o mundo do trabalho e a continuidade dos estudos. Por fim, aborda-se a problemática da diversificação da oferta do ensino médio e seus riscos na acentuação das desigualdades, questão mais uma vez reacendida na comparação das expectativas dos alunos do tempo integral e do parcial.

Palavras-chave: Ensino médio. Juventude(s). Escola. Território vulnerável. 


\section{INTRODUÇÃO}

Etapa recente da educação obrigatória ${ }^{2}$, o ensino médio continua sendo um grande desafio no Brasil. Se os problemas são velhos conhecidos, o novo estatuto obrigatório do nível de ensino reforça a necessidade de o Estado assegurar o direito dos jovens ao acesso a essa etapa, bem como a permanência nela, com a adequada qualidade.

Se é verdade que foram feitos avanços nas últimas década, eles se mostram ainda insuficientes. Atualmente, já temos $82,6 \%$ dos jovens com idade de 15 a 17 anos na escola (PNAD/IBGE, 2014). Contudo, apenas 58\% dos alunos matriculados no ensino médio estão com a idade devida, o que revela sérios problemas de distorção idade-série. Nas duas últimas décadas, houve, certamente, uma acentuada evolução nas taxas de conclusão entre jovens com até 19 anos $^{3}$ - de 17,7\% (1995) para 56,7\% (2014). Mas isso significa que ainda temos $43,3 \%$ nessa faixa sem concluir o nível de ensino. Os jovens de 15 a 17 anos são, hoje, além disso, o grupo mais atingido pela exclusão escolar: mais de 1,7 milhão deles estão fora da escola (VOLPI; SILVA; RIBEIRO, 2014). Por fim, no que diz respeito a indicadores de resultado, o ensino médio não tem atingido as metas do Índice de Desenvolvimento da Educação Básica (Ideb) ${ }^{4}$ desde 2011. 0 indicador de fluxo para as escolas estaduais é de $82 \%$, ou seja, a cada 100 alunos, 18 foram reprovados (Cf. IDEB/INEP, 2015).

Quando se considera o direito à educação desses jovens, portanto, o cenário demanda, seguramente, de um lado, a formulação e a implantação de políticas públicas para que - tal como define a legislação - o Estado cumpra seu dever de assegurar o acesso a essa etapa obrigatória da educação básica, sobretudo aos jovens de territórios socialmente vulneráveis, ainda mais suscetíveis à negação de direitos. Afinal, o acesso ao ensino médio está ligado, justamente nessa fase da vida, às perspectivas e possibilidades de futuro pessoal e profissional. Acaba por sinalizar aos jovens os projetos de vida desejáveis, mas também possíveis e prováveis (BOURDIEU, 1998), no

Conforme Emenda Constitucional n 59, de 11 de novembro de 2009.

Considerando a idade adequada para cursar o ensino médio a de 15 a 17 anos, e a distorção idade-série como a proporção de alunos com mais de dois anos de atraso escolar, optamos por trabalhar com o recorte de jovens até 19 anos para ampliar a proporção de concluintes do ensino médio isolando a interferência da taxa da distorção idade-série. Disponivel em: 〈http://www.edudatabrasil.inep.gov.br/glossario.html〉. Acesso em: 12 dez. 2016.

4 Indicador bianual que varia de 0 a 10 e que utiliza a taxa de aprovação e médias de desempenho no Sistema de Avaliação da Educação Básica (Saeb)/Prova Brasil para calcular seus resultados. 
que caberia ao Estado, por meio de políticas públicas, dirimir as influências da posição social de origem na trajetória desses estudantes, garantindo oportunidades (educacionais, culturais, sociais, econômicas) iguais a todos.

Ao mesmo tempo, porém, e de modo complementar, esse cenário exige também, por outro lado, conhecer quem são esses jovens alunos do ensino médio - sobretudo esses que vivem em contextos de vulnerabilidade social, apreendendo suas principais expectativas e desafios, em especial, sua relação com a escola e com o saber.

As relações entre jovens e educação, ou entre educação e juventude(s), como afirma Sposito (2008, p. 84), “podem ser analisadas a partir de diversos ângulos” e - complementa-se aqui - a partir de diferentes interesses de pesquisa, perspectivas e abordagens teóricas. Estudos, hoje clássicos na sociologia da educação, se dedicaram, nos anos 1960-70, a esmiuçar os vínculos entre a origem social dos estudantes e seu destino escolar, explicitando as relações imbricadas entre educação, classes sociais e reprodução de instâncias de dominação e poder (BAUDELOT; ESTABLET, 1971; BOURDIEU; PASSERON, 1970; BOURDIEU, 1979; BOWLES; GINTIS, 1976). Segundo Charlot (1996), muito esforço se dedicou, no período, para o estudo do fracasso escolar, sobretudo nas classes ditas desfavorecidas, deixandose de lado histórias singulares dos alunos - importantes "não apenas para se compreender as possibilidades de casos marginais, mas também para dar a conhecer formas modernas de desigualdade social no terreno escolar" - bem como que "sentido tem para a[s] criança[s]" - e, no caso aqui, jovens - "o fato de ir à escola e aprender coisas", o que os mobiliza no campo escolar (CHARLOT, 1996, p. 48).

Em Charlot (1996, 2001) encontramos questões que iluminam as diferentes relações que o aluno pode ter com a escola e com o saber. Ao estudar a relação de estudantes de periferia na França, o autor evidenciou que "aprender não significa a mesma coisa para todos"; o saber pode, por exemplo, ser encarado como um fim em si mesmo e como uma possibilidade de ampliação dos horizontes - "para alguns jovens estudar significa se apropriar dos saberes"; ou como algo mais instrumental e externo, a ser adquirido tendo em vista finalidades práticas quando "a relação com a escola não implica relações com o saber: estudar significa adquirir obrigações profissionais de escolar" (CHARLOT, 1996, p. 58). Pode, ainda, para outros jovens, ser algo distante e pertencente a um grupo do qual não faço parte ou não desejo pertencer, por isso seria recusado. 
Nos últimos 20 anos aumentaram consideravelmente os estudos - em termos nacionais, em especial na área da educação, mas também, mais amplamente, nas ciências sociais e no serviço social (DAYRELL; CARRANO, 2009; SPOSITO, 2009) - que têm se dedicado às relações dos jovens com a educação formal (i.e., a escola, os saberes por ela transmitidos, a cultura escolar) e não formal (i.e., outros saberes, a relação dos jovens com a educação e a cultura de maneira mais ampla, as culturas juvenis e seus modos de sociabilidade etc.) (Cf. ABRAMOVAY; CASTRO; WAISELFISZ, 2015; CARRANO; MARTINS, 2011; DAYRELL, 2007; DAYRELL; CARRANO; MAIA, 2014; KRAWCZYK, 2011; PEREIRA, 2015, 2016; SPOSITO, 2005, 2008, 2009).

O objetivo deste artigo é, a partir de uma primeira pesquisa exploratória e dialogando com parte dessa literatura, trazer elementos para esse debate com base na experiência de estudantes de escolas públicas estaduais situadas em territórios de maior vulnerabilidade social no Brasil. Partiu-se dos dados coletados no âmbito da pesquisa "Políticas para o ensino médio: o caso de quatro estados", que é tema deste número da Cadernos Cenpec. Como já se indicou em outros artigos publicados neste número da revista, esta investigação buscou analisar as políticas para o ensino médio de quatro estados brasileiros (CE, PE, GO, SP), a fim de apreender o modelo que as sustenta - especialmente no texto "Políticas para o ensino médio: o caso de quatro estados" (BATISTA et al., 2016) ${ }^{5}$-, bem como o modo como escolas e educadores respondem a elas - abordado no trabalho "Reações das políticas educacionais estaduais nas escolas: um estudo de caso em escolas do Ceará, Goiás, Pernambuco e São Paulo" (VIEIRA et al., 2016).

Um dos instrumentos utilizados para auxiliar na consecução desse segundo objetivo consistiu num questionário aplicado aos estudantes das escolas pesquisadas. Interessou, por meio dele, apreender diferentes dimensões ligadas ao processo de escolarização dos jovens, tais como suas relações com a escola, com seus pares e professores/gestores, com o currículo, com o saber, mas também aspectos ligados à sociabilidade e suas expectativas em relação ao futuro, entre outros. São questões que parte da sociologia da educação e da juventude vem buscando explorar, bem como educadores e formadores que trabalham com esse público, tendo em conta os papéis da escola como instituição oficial de transmissão do saber, como instância central

Batista et al. (2016) consolidam os principais achados da pesquisa realizada nos quatro estados. Neste trabalho, além de apreender modelos de políticas para o ensino médio, são descritos os critérios de seleção de escolas que participaram da amostra, o que evidenciou o perfil sociodemográfico distinto da matrícula do alunado nos dois tipos de oferta (parcial e integral). 
de socialização no mundo moderno e contemporâneo, mas também como importante instância, para muitos grupos sociais e famílias, que organiza suas possibilidades de reprodução social, como analisado nos trabalhos supracitados desta mesma edição.

Outro interesse central do artigo foi - dado o papel central das condições escolares na conformação das relações com a própria escola - examinar como a diferenciação das oportunidades educacionais (e, portanto, da própria experiência escolar) promovida pela diversificação da matrícula entre tempo integral e parcial afeta a relação dos jovens com a escola.

O texto está organizado em três partes: 1) aspectos metodológicos e caracterização da amostra, explorando os dados contextuais dos respondentes; 2) a relação dos jovens com a escola e com o saber; e 3) considerações finais.

ASPECTOS METOdOLÓGICOS, CARACTERIZAÇÃO DA AMOSTRA E CONSIDERAÇÕES INICIAIS

Analisaram-se 669 questionários, preenchidos por alunos de 24 escolas públicas estaduais ${ }^{6}$, distribuídas em 17 municípios - seis escolas em cada um dos estados estudados. Foram priorizadas unidades localizadas em territórios com maior vulnerabilidade socioeconômica. A amostra contempla estudantes das periferias de grandes centros urbanos (regiões metropolitanas), de municípios de médio e de pequeno porte, este com alto índice de ruralidade, marcados, portanto, por um contexto de desigualdade social7.

Os questionários foram aplicados, em $2015^{8}$, aos alunos da $2^{\text {a }}$ série do ensino médio, sendo 172 do Ceará, 188 de Goiás, 157 de Pernambuco e 152 de São Paulo, respectivamente 25,7\%, 28,1\%, 23,5\% e 22,7\% da amostra. Tal instrumento foi elaborado pela equipe central de coordenação junto das equipes de pesquisadores locais, constituídas em cada um dos quatro

6 No Brasil, $84,45 \%$ das matrículas do ensino médio estão nas redes estaduais (INEP, 2015).

7 As regiões potencialmente vulneráveis foram identificadas com base em indicadores como o Índice de Desenvolvimento Humano de Municípios (IDH-M) e o Índice de Desenvolvimento Humano de Bairros (IDH-B). 0 alto índice de ruralidade foi estimado pela proporção de $70 \%$ de habitantes em zona rural (Cf. BATISTA et al., 2016).

8 A coleta de dados precedeu a Medida Provisória nํㅜ 746, de 2016, e a recente aprovação da Lei no 13.415, sobre a Reforma do Ensino Médio. Sobre a atual lei, ver conteúdo disponível em: 〈http://legis.senado.leg.br/legislacao/ListaNormas.action?tipo_norma= LEI\&numero=013415\&data=2017\&SUBMIT1=Pesquisar. Acesso em: 27 mar. 2016. 
estados. Após coletados, os dados foram tabulados, tratados e analisados. Priorizou-se um exame mais geral das informações, de modo a agrupar os dados dos estados, sinalizando semelhanças e diferenças entre os jovens que estudam em escolas de tempo integral e parcial.

No Brasil, como se sabe, a oferta do ensino médio pode ocorrer de diversas formas: nos turnos matutino, vespertino e noturno, sendo que no diurno é possível cursar o ensino médio em período parcial ou integral ${ }^{9}$. Do total de questionários aqui analisados, 52,62\% (352) são de estudantes de escolas integrais ${ }^{10}$, e 47,38\% (317) do período parcial - sendo que o Brasil possuía, em 2014, apenas 4,7\% de alunos em período integral, de acordo com dados do Instituto Nacional de Estudos e Pesquisas Educacionais Anísio Teixeira (Inep). Isso significa que o percentual de estudantes de período integral está superestimado. Além disso, dos estudantes matriculados em período parcial que participaram desta investigação, apenas 9,78\% (31) ${ }^{11}$ estão matriculados no turno noturno. Essa pequena representação se deve ao fato de apenas uma turma ter sido observada na pesquisa empírica, e em Goiás. Como essa amostra está sub-representada, a análise aqui realizada se dedicará aos alunos do turno diurno.

Em razão de os questionários terem sido aplicados junto a alunos da $2^{\text {a }}$ série do ensino médio, a idade considerada adequada seria 16 anos. Jovens na faixa etária entre 16 e 17 anos representam, na amostra, 45,44\%; um percentual de $4,78 \%$ possui 18 anos ou mais; porém, aqui, o percentual de alunos nessa faixa de idade é cerca de duas vezes maior no período parcial (6,94\%) que no integral (2,84\%), diferença também observada no grupo de alunos com menos de 16 anos: são 37,54\% no parcial e 52,56\% no integral. Esses dados indicam, mais uma vez, como em outros artigos deste número da Cadernos Cenpec, um perfil sociodemográfico distinto na matrícula dos dois

9 Considera-se educação em tempo integral a oferta educacional acima de 7 horas. A educação integral se constitui num projeto educativo integrado, englobando desenvolvimento intelectual, físico, artístico, cultural, com conhecimentos sobre cidadania, direitos humanos e os das crianças e adolescentes, entre vários outros. No Brasil, é possível encontrar as modalidades técnica e profissional neste tipo de oferta. Mais informações estão disponíveis em: 〈http://educacaointegral.mec.gov.br/?id=9〉. Acesso em: 16 jan. 2017.

10 Diferente da definição de matrícula integral utilizada pelo Inep, considerou-se como "aluno integral" aquele cuja turma tinha carga horária igual ou maior a 7 horas diárias, visto que nossa unidade de análise é a escola e não o aluno.

${ }^{11}$ O percentual de matrículas do ensino médio noturno no Brasil é de $28,11 \%$, no Ceará corresponde a 18,05\%, em Goiás 31,77\%, Pernambuco 21,28\% e São Paulo 36,68\% (Censo Escolar 2015). 
tipos de oferta. Comparando com dados nacionais do Censo Escolar (2015), percebe-se que esse padrão se mantém: a distorção idade-série no período parcial (29,82\%) é duas vezes maior que no integral (13,84\%). Na amostra, apenas Pernambuco possui, ainda que de maneira bastante discreta, mais jovens com 18 anos ou mais $(5,15 \%)$ matriculados no integral que no parcial $(4,76 \%)$; o estado é uma das unidades federativas com maior oferta do ensino médio integral, com uma política de oferecer ao menos uma escola integral em cada município, e parece possibilitar o acesso a alunos de composição social um pouco mais diversificada, o que não foi percebido nos demais estados observados.

A maior parte da amostra (55,75\%) é composta por pessoas do sexo feminino, tanto no período parcial como no integral nos quatro estados, embora com uma distribuição um pouco mais homogênea em São Paulo. Este perfil se assemelha ao quadro nacional - 56,45\% feminina no integral e 53,50\% no parcial - conforme o Censo Escolar (2015). No quesito raça/cor, identificamse que, em dois dos estados analisados, são maiores os percentuais de alunos brancos no integral que no parcial - mais que o dobro em Pernambuco (30,15\% no integral para $14,29 \%$ no parcial) e em menor proporção em Goiás (34,62\% para $25,93 \%)$.

Embora a maior parte dos estudantes da amostra habite nos arredores da escola (56,8\%), quase $15 \%$ dos jovens do período integral moram em outro município, dado que, por um lado, sugere a possibilidade de uma mobilização das famílias e dos jovens para a matrícula nessas instituições e, por outro, evidencia que vagas deixam de ser ocupadas por moradores do entorno vulnerável. Em Pernambuco, chama a atenção que 29,41\% dos alunos do período integral morem em outra cidade, o que suscita questões sobre o atendimento nos municípios de origem, visto que cada cidade teria, pelo menos, uma escola integral. A política de oferta de ao menos uma escola integral em cada município estaria aumentando a demanda e, por isso, alunos de cidades vizinhas estariam procurando atendimento fora de seu domicílio? De todo modo, tal informação sugere a tendência de uma concorrência por vagas nessas escolas, como reiterado em outros artigos desta edição (i.e., VIEIRA et al., 2016).

A reprovação tende a ser maior entre os alunos das escolas de tempo parcial, nas quais $27,76 \%$ deles já foram retidos alguma vez, contra $10,8 \%$ do integral. Em São Paulo encontram-se os menores percentuais - $13,79 \%$ no período parcial e 6,15\% no integral -, possivelmente reflexo da política de progressão 
continuada implantada nas escolas públicas do estado desde 1998 (VIÉGAS; SOUZA, 2006).

Fruto do aumento da demanda e da oferta de vagas no ensino médio, após os anos 1990, nota-se no Brasil um crescimento do tempo médio de estudos quando há uma comparação intergeracional. Ou seja, a atual geração escolar tende a ser mais escolarizada que a de seus pais (Cf. SPOSITO, 2005; SPOSITO; SOUZA, 2014), o que se reflete nesta pesquisa. Cerca de metade dos pais (mais pontualmente, $54 \%$ das mães e $50,22 \%$ dos pais) tem escolarização inferior à dos filhos, ou seja, apenas o ensino fundamental - o ensino médio foi concluído por $35,87 \%$ das mães e $33,48 \%$ dos pais. Possivelmente, esse quadro está relacionado com o fato de a composição da amostra englobar escolas e, consequentemente, famílias de regiões de maior vulnerabilidade socioeconômica ${ }^{12}$.

Ainda em relação à escolarização dos pais, diferenças entre integral e parcial aparecem de modo destacado. A escolaridade dos pais, na amostra, é maior entre alunos do integral em relação ao parcial - no integral, 43,47\% das mães terminaram o ensino médio enquanto que, no parcial, apenas $27,44 \%$. Nesse quadro, o capital cultural, alinhado ao econômico - que veremos abaixo pode ajudar a explicar as origens da melhor adaptação às escolas de tempo integral de jovens considerados - sob o ponto de vista dos agentes escolares - "alunos adequados" a esse tipo de estabelecimento.

Na nossa amostra, $41,85 \%$ das famílias dos jovens se encontram na faixa de renda mais baixa, que vai até 1,5 salário mínimo ${ }^{13}$ - dado intuitivo por analisarmos territórios vulneráveis. Os alunos do período integral, porém e uma vez mais, tendem a ter maior renda que os alunos do regime parcial.

Nos dois estados do Nordeste - em que o nível socioeconômico dos alunos do ensino médio é, globalmente, inferior aos de Goiás e de São Paulo -, a concentração na faixa de renda mais baixa, mesmo que predominante nos dois tipos de escola, é menor nas unidades de tempo integral do que nas de tempo parcial, atingindo $53,60 \%$ no integral e $74,47 \%$ no parcial na amostra cearense, e 46,32\% e 85,71\% na pernambucana, respectivamente. Em Goiás, $46,15 \%$ dos alunos do período integral se concentram na segunda faixa de

12 Ressaltando o impacto desse fator na escolarização, Ferreira e Veloso (2003, p. 482) destacam que "a probabilidade do filho de pais com ensino superior completo também completar seus estudos universitários é cerca de $40 \%$, se o indivíduo reporta ser negro ou pardo, e aproximadamente $62 \%$ para brancos".

13 De acordo com o Decreto 8.618/2015, o valor de referência do salário mínimo, em 1으 de janeiro de 2016, era $R \$ 880,00$. 
renda - de 1,5 a 3 salários mínimos -, enquanto que, no parcial, 35,19\% estão na faixa mais baixa. Já em São Paulo, as desigualdades econômicas se ampliam, com a maior concentração de estudantes do integral $(33,85 \%)$ na terceira faixa - de 3 a 4,5 salários mínimos - enquanto a maior concentração do parcial $(29,89 \%)$ encontra-se na primeira faixa.

Assim, embora a diversificação da oferta no ensino médio já ocorresse há muito, parece adquirir grau mais acentuado com a emergência de modelos de ensino médio de período integral e ensino médio integrado à educação profissional (caso do Ceará), explicitando, claramente, condições de atendimento desiguais, mesmo em escolas localizadas em territórios mais vulneráveis. Se antes se reconheciam as agudas distinções na oferta de ensino médio (diurno e noturno, urbano e rural), esta nova oferta, que ocorre concomitantemente às demais, impõe critérios, relacionados a diferenças sociais - especialmente aquelas indicadas pela escolaridade dos pais, que levam à diferenciação da experiência escolar dos jovens. Esses fatores certamente tendem a se manifestar na relação dos jovens com escola. É o que se examinará a seguir.

\section{RELAÇÃO DOS JOVENS COM A ESCOLA E COM O SABER: ANÁLISE DOS DADOS}

\section{Relação dos jovens com a escola}

Para uma primeira aproximação com o que os jovens da nossa amostra pensam sobre a escola é interessante apreender as razões por eles apontadas para se estudar em determinada escola e não em outra. A reputação da unidade escolar foi indicada como o principal motivo: $66,07 \%$ dos alunos assinalaram que a escola em que estudam é considerada boa. Essa alternativa representa a percepção de quase $80 \%$ dos alunos do período integral, mas com forte discrepância em relação aos estudantes do parcial (50,79\%), especialmente em São Paulo e Goiás. Em Goiás, essa opção é assim percebida por 80,77\% dos que se matricularam em escolas de tempo integral, contra $49 \%$ do parcial. E em São Paulo, 87,77\% dos estudantes do integral creem que se matricularam numa escola de melhor reputação, enquanto apenas $41 \%$ daqueles do período parcial compartilham a mesma crença. Ainda, para $88 \%$ estudantes cearenses que se matricularam em escolas integrais, a opção se deu pela boa reputação desses estabelecimentos, contra $64 \%$ dos que se matricularam em escolas de período parcial. Somente em Pernambuco nota-se uma convergência nas percepções a respeito da boa reputação da escola, independentemente do fato de ser de tempo parcial ou integral. Entretanto, destaca-se que a primeira, 
surpreendentemente, contrariando a regularidade apreendida na análise dos demais estados, tende a ser percebida, por seus alunos, como a de melhor reputação (76,19\% dos estudantes do parcial, contra $68 \%$ do integral). Podem ser levantadas diferentes hipóteses para explicar essa diferença, mas há um possível efeito amostral em Pernambuco. Algumas das escolas de período parcial selecionadas - embora inicialmente descapitalizadas pela criação de estabelecimentos de tempo integral na vizinhança - conseguiram firmar uma reputação junto à comunidade por meio de diferentes estratégias, descritas no artigo de Vieira et al. (2016). Uma delas já detinha, antes da criação da escola de tempo integral, uma forte reputação, por isso é possível supor que esses dados de contexto tenham pesado na avaliação dos estudantes.

A grande maioria dos alunos (82,36\%) acredita que a escola se preocupa com seu futuro. Observa-se, porém, mais uma vez, uma diferença na distribuição desse resultado entre estudantes do período integral (90\%) e do parcial (75\%). Do mesmo modo, é elevada a diferença no percentual de estudantes que acredita que os profissionais da escola apostam na continuidade dos estudos dos alunos, conforme o período $-68,31 \%$ do integral contra $15,55 \%$ do parcial. Os jovens se manifestaram também sobre a crença que eles mesmos têm em relação à continuidade dos estudos ${ }^{14} \mathrm{e}$, de acordo com os resultados, cerca de $60 \%$ concordam que vão continuar os estudos após o ensino médio, contra $14,5 \%$ que discordam. A decomposição desse dado revela que os estudantes do integral $(71,59 \%)$ parecem estar mais confiantes na continuidade dos seus estudos que os do parcial (50,47\%).

Mais baixos entre os jovens do parcial, os percentuais que indicam descrença em seu potencial - tal como projetado em seu futuro e nas expectativas de seus professores e da escola - merecem ser discutidos, tendo em vista a influência, destacada pela literatura, desse aspecto nos resultados educacionais e na própria relação que o jovem pode estabelecer com a sua experiência escolar. Essas percepções negativas são também reforçadas, com exceção dos estudantes pernambucanos, pela crença menos positiva na reputação da escola em que estudam. O experimento de Robert Rosenthal e Lenore Jacobson (1992), por exemplo, comprovou que professores que têm uma visão positiva dos alunos tendem a estimular os estudantes que, por sua vez, tendem a obter melhores resultados. 0 inverso também ocorre: professores que não têm apreço por seus alunos adotam posturas que comprometem negativamente o desempenho dos educandos ${ }^{15}$. Assim, ainda

${ }_{14}$ Neste item do questionário foi elevada a quantidade de alunos que não soube responder (22,87\%), 0,45\% das respostas foi anulado e $0,60 \%$ não respondeu a este item.

${ }_{15}$ Experimento desenvolvido em 1968 com alunos de uma escola primária da Califórnia 
que todos estudem em escolas localizadas em vizinhanças mais vulneráveis, é provável que tenham rendimentos diferentes e destinos escolares e sociais distintos, uma vez que compartilham crenças desiguais em relação ao valor de sua escola e às suas possibilidades futuras.

Buscando apreender o grau de satisfação dos estudantes com a escola, a maioria dos alunos (80\%) não mudaria de estabelecimento, reforçando a ideia de que os jovens parecem gostar da unidade de ensino que frequentam. Entretanto, o nível de satisfação tende a ser ligeiramente inferior nas escolas de período parcial (77\%) e, no caso de Goiás, a relação se inverte: 78\% não gostariam de sair das escolas de período parcial, contra $62 \%$ das de tempo integral.

Ao identificar o que os alunos mudariam em sua escola, a estrutura física aparece em primeiro lugar, conforme o Gráfico 1. Este item também foi o mais indicado entre os alunos de escolas integrais (17,94\%), cujas instalações, principalmente as de caráter técnico ou profissionalizante, costumam apresentar melhores condições que as demais (CASTRO; LOPES, 2011).

Gráfico 1 - 0 que mudaria nas escolas segundo os jovens

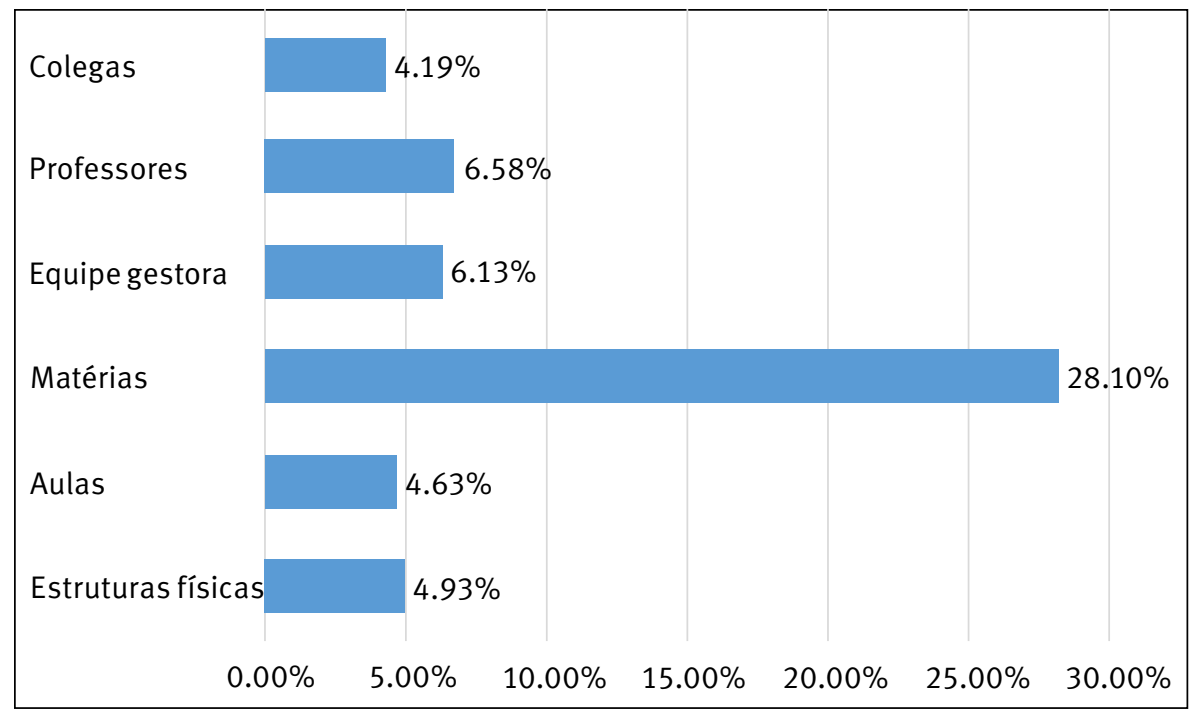

Fonte: Elaborado pelos autores a partir de questionários aplicados junto aos jovens em 2015.

Nota: Este item do questionário solicitava o ordenamento, por prioridade, das alternativas que mais agradavam aos estudantes. Em alguns instrumentos não houve atendimento à comanda de preenchimento, e por essa razão foram considerados válidos 356 questionários, ou seja, 53,21\% da amostra. Ademais, apenas oito questionários foram considerados válidos no recorte Goiás integral, o que sugere cautela na interpretação dos dados.

concluiu que, ao elevarem suas expectativas sobre aqueles alunos, os professores mudaram sua atitude em relação a eles, tornando-se mais encorajadores, receptivos e envolvidos com seu aprendizado, o que criou um compromisso que influenciou positivamente o desempenho deles. 
As desigualdades existentes entre a infraestrutura das escolas brasileiras (rede pública x privada, escolas diurnas x noturnas, urbanas $x$ rurais, e entre as regiões) já foram anunciadas em alguns estudos (i.e., LEÃO; DAYRELL; REIS, 2011; SOARES NETO et. al., 2013). Utilizando dados do Censo Escolar 2011, Soares et al. (2013) analisaram dados de 194.932 escolas da rede pública e privada, das zonas rurais e urbanas, e mostraram que mais de $44 \%$ das escolas da educação básica brasileiras ainda apresentam uma infraestrutura escolar elementar - apenas com aspectos imprescindiveis para o funcionamento de um prédio escolar, como água, banheiro, energia, esgoto e cozinha, de forma que se pode afirmar que o problema de infraestrutura é amplo. No entanto, em territórios de maior vulnerabilidade social - como no caso da nossa amostra - isso pode ganhar maior ênfase, visto que neles a escola é, além de um espaço para o desenvolvimento da aprendizagem de conhecimentos cientificamente acumulados, um importante equipamento social, podendo ser um dos poucos espaços que oferecem uma estrutura para lazer, esporte, arte e cultura quando comparado ao entorno da comunidade.

Relação dos jovens com os colegas e outras sociabilidades

O papel social que a escola tem na vida dos jovens pode ser observado, nos dados da pesquisa, na resposta ao que o que mais gostam na escola. "Os colegas" é a opção mais mencionada, com $22,27 \%$ de indicações, conforme o Gráfico 2. Nos quatro estados da amostra isso é reiterado, demarcando que a escola, além de um local de saber, é um dos principais espaços de sociabilidade dos jovens. 
Gráfico 2 - 0 que os jovens mais gostam na escola

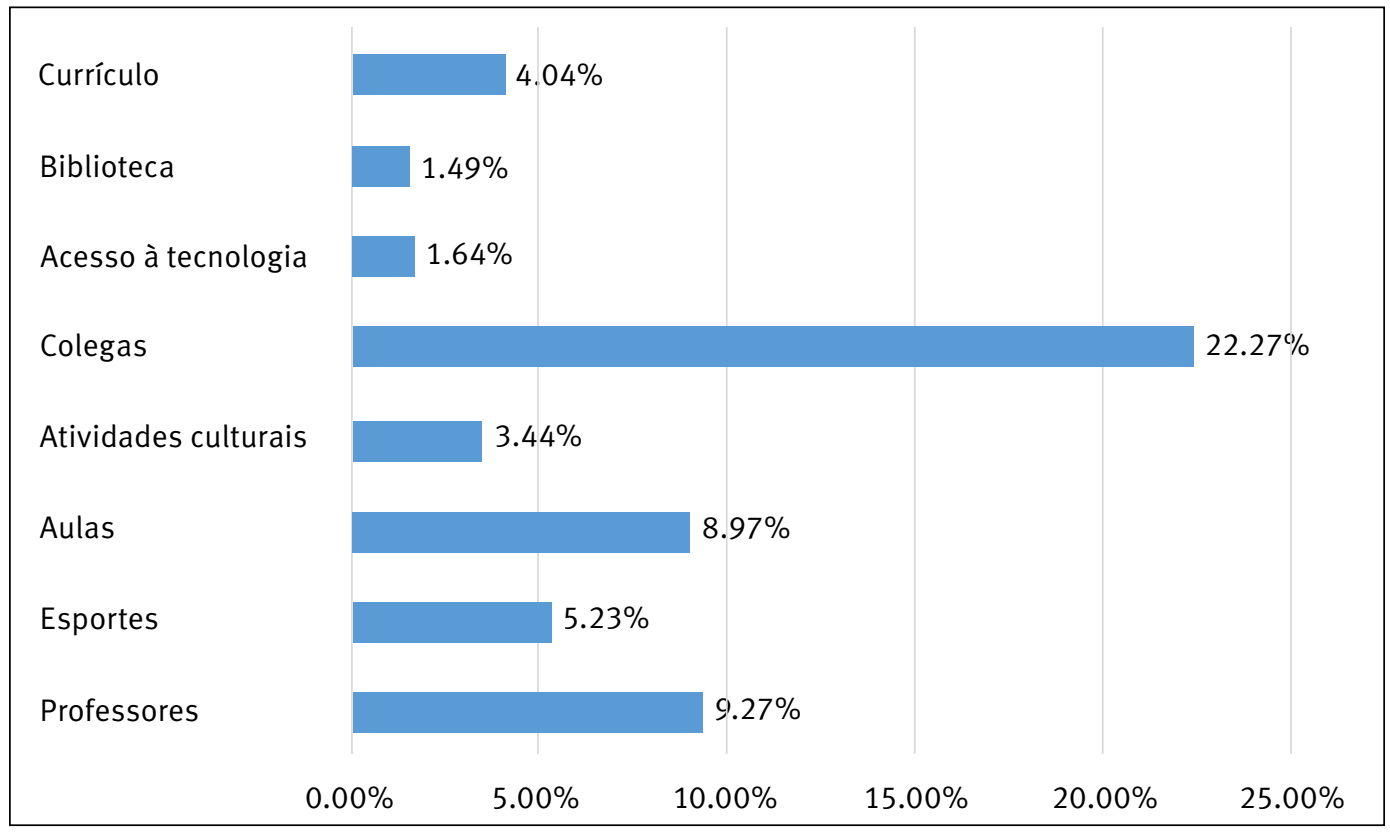

Fonte: Elaborado pelos autores a partir de questionários aplicados junto aos jovens em 2015.

Nota: Este item do questionário solicitava o ordenamento, por prioridade, das alternativas que mais agradavam aos estudantes. Em alguns instrumentos não houve atendimento à comanda de preenchimento, e por essa razão houve uma perda de cerca de $30 \%$ das respostas.

Para Abramovay, Castro e Waiselfisz (2015, p. 93) “fica claro que as relações entre os alunos influenciam suas avaliações e até a permanência na escola. Ali desfrutam de convivência e se ligam afetivamente uns aos outros”. Assim, as relações sociais na escola são componentes básicos do clima escolar, e estão ligados às relações que os estudantes estabelecem com a própria escola.

Ocupando o segundo e o terceiro lugar entre as indicações do que os estudantes mais gostam na escola estão “os professores" (9,27\%) e "as aulas" $(8,97 \%)$. O resultado sugere que os jovens parecem ser chamados a assinalar as opções que envolvem relações interpessoais, figuradas no convívio com os colegas e com os professores. As relações estabelecidas no cotidiano escolar - incluindo alianças e conflitos - compõem um conjunto de vivências que dão forma e influenciam os sentidos atribuídos à experiência escolar.

Considerando a amostra da pesquisa, é relevante se apropriar das palavras de Dayrell (2007, p. 1121) ao sublinhar que "no caso dos jovens pobres, a sociabilidade ganha uma maior dimensão, à medida que a ausência de equipamentos públicos e de lazer nos bairros desloca para a escola muitas das expectativas de produção de relações entre os pares". Portanto, as relações, seja entre alunos, professores e gestores, ganham destaque nesse contexto. 
Ainda compreendendo a importância das práticas de sociabilidade para a juventude, buscou-se apreender também as principais formas de convívio estabelecidas pelos jovens ${ }^{16}$, verificando as relações que estes estabelecem com diferentes tipos de atividades, como expõe o Gráfico 3.

Gráfico 3 - Grupos a que os alunos pertencem

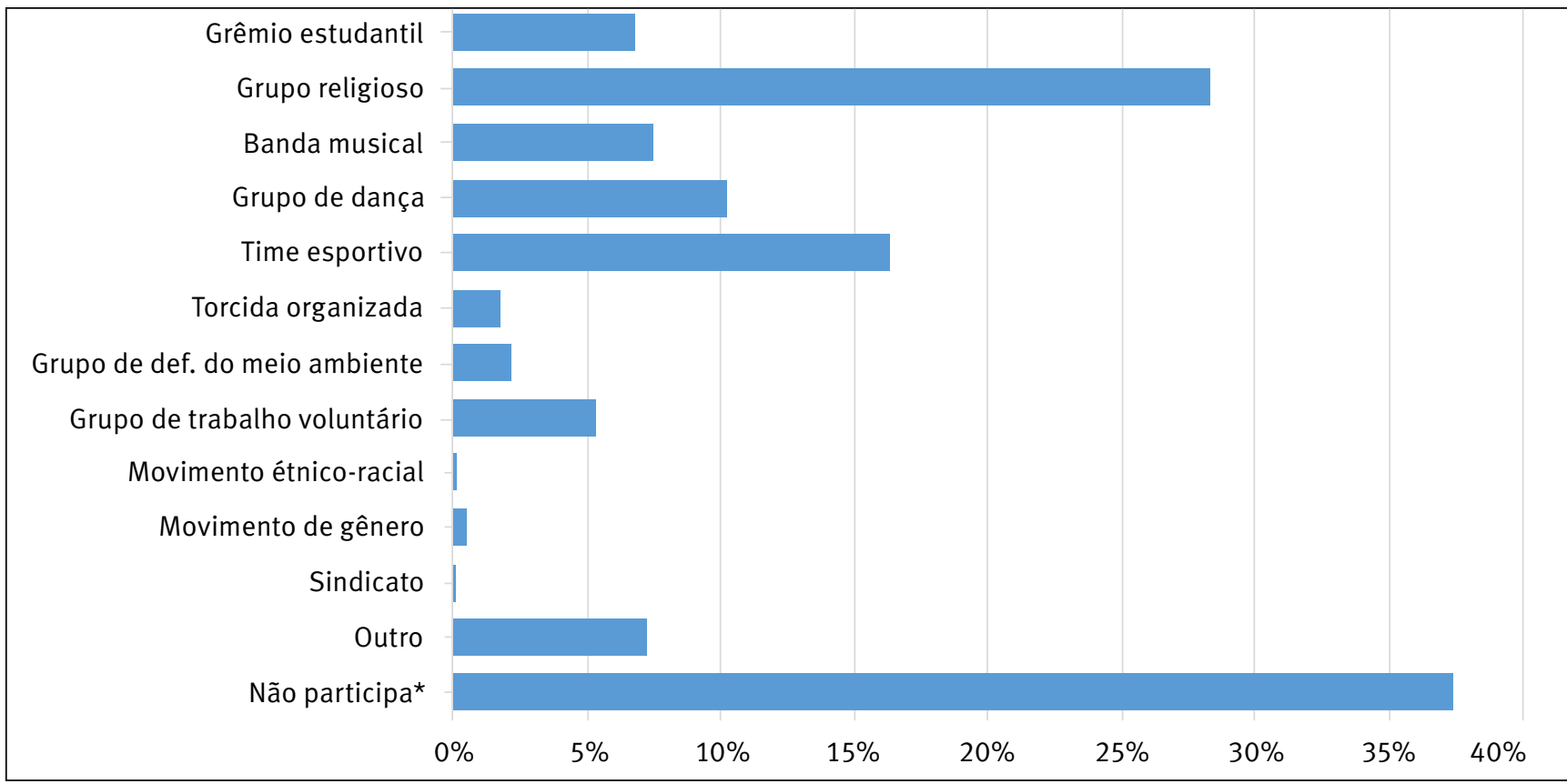

Fonte: Elaborado pelos autores a partir de questionários aplicados junto aos jovens em 2015.

Nota: Por se tratar de uma questão optativa no questionário, as ausências de respostas (cerca de 30\%) não geram problemas para o tratamento dos dados. Ademais, esta pergunta não se refere, necessariamente, aos grupos a que os alunos pertencem na escola, ampliando seu resultado para as sociabilidades juvenis.

Apesar do elevado percentual na alternativa "não participa" (37,52\%), a opção "grupo religioso" concentrou a maior parte das respostas $(28,40 \%)$. Esta vinculação é maior entre os jovens do período integral (31,53\%), do que do parcial (24,92\%). Goiás e Ceará são os dois estados com maior incidência entre os jovens do integral, com $41,60 \%$ no integral e $26,67 \%$ no parcial (CE); e $42,31 \%$ e $32,10 \%$ no parcial (GO), respectivamente. Todavia, em São Paulo a diferença entre o percentual do integral $(27,69 \%)$ e do parcial $(9,20 \%)$ é até um pouco mais acentuada. A importância da religião para jovens de meios vulneráveis é amplamente atestada pela literatura (GOMES, 2007). Para Scott e Cantarelli (2004, p. 377), “quando um jovem faz parte de uma igreja, opta

16 A pergunta no instrumento aplicado junto aos jovens não esclarece se as opções assinaladas são internas ou externas à escola ("Você pertence a algum grupo específico? Marque mais de uma opção se necessário"). 
por pertencer a 'uma comunidade moral', compartilhando valores que servem para referenciar sua vida, tornando-se distinto dos outros que participam ou não de outras religiões ou crenças". Essa relação ultrapassa os muros da igreja e se estende ao cotidiano. É comum se encontrarem, mesmo sem finalidade religiosa, e a amizade entre eles favorece a formação de redes de sociabilidade. Ela se estende também à escola, já que tende a haver certa coincidência entre disposições religiosas e escolares - especialmente aquelas de natureza disciplinar, como o "respeito", certa "conformidade" e uma valorização da autoridade e da lei que terminam por favorecer a ação da escola (quando esta não tende a afirmar seu caráter laico e uma forte abertura à diversidade).

O segundo maior grupo aglutinador dos jovens, tanto no período integral quanto no parcial, é “time esportivo", com $16,44 \%$ das respostas - 14,77\% no integral e $18,30 \%$ no parcial. Não muito atrás, aparecem os grupos de dança $(10,31 \%)$ e banda musical (7,62\%). Surpreende a posição dos grêmios estudantis nesse quadro, indicado por apenas $6,88 \%$ dos alunos, sugerindo a necessidade de se discutir essa instância como espaço de participação e engajamento juvenil, fortemente incentivada pelas escolas de tempo integral da maior parte dos estados. Pernambuco foi a unidade da federação com maior percentual (16,91\% no integral), enquanto que Goiás não teve estudantes do período integral pertencendo a grêmios.

A relação dos jovens com o saber, como já citado, é outro aspecto que a pesquisa visa explorar, ainda que de modo inicial.

Relação dos jovens com o saber

Encontra-se em Charlot (1996, p. 55) uma forte correlação entre "gostar do professor" e "gostar da matéria", ressaltando a importância das relações interpessoais entre professor e aluno como um elemento que fortalece a relação com o saber entre jovens de periferia parisiense, o que também pode ser pensado no caso brasileiro. Em nosso caso, porém, os dados evidenciam uma pouca adesão a "gostar dos professores". Se retomarmos as preferências dos jovens em relação à escola, expostas no Gráfico 2, "os professores" aparecem na segunda posição, mas com uma frequência de apenas 9,27\%, e “as aulas” aparecem na terceira posição, com uma frequência de 8,97\%.

A opinião dos alunos sobre as aulas é, de modo geral, positiva. Mais da metade consideram as aulas "interessantes" (53,66\%); um percentual menor as considera "estimulantes" (12,71\%). Porém, é razoável o percentual de 
alunos que as avalia como "monótonas" (15,84\%) ou "repetitivas" (13,60\%). Destaca-se 0 alto o percentual de jovens que consideram as aulas repetitivas (34,62\%) no integral, e aulas monótonas $(29,01 \%)$ no parcial em Goiás. Uma hipótese que pode ajudar a explicar esse fenômeno é a preparação para exames e vestibulares - também encontrada em outros estados - ou mesmo a própria inadequação de formato e/ou conteúdo aos interesses dos jovens do ensino médio.

Para cerca de $40 \%$ dos alunos, a escola e seus professores contribuem para melhorar seu desempenho escolar ${ }^{17}$, reforçando o papel dos docentes no aprendizado de conteúdos escolares - especialmente no ensino médio, cujos temas dificilmente seriam expostos por outros meios que não os escolares. 0 esforço do próprio estudante e o apoio da família ocuparam, juntos, o segundo lugar nas indicações (20,78\%), demarcando o reconhecimento desses fatores para o sucesso escolar dos jovens, suporte esse que, especialmente na percepção dos estudantes, se articula - em particular o "esforço", em oposição à “desenvoltura” e à "criatividade”, características comuns nos discursos de jovens das camadas com alto capital cultural - com sua aparente relação "escolar" com o estabelecimento de ensino.

Esses dois modos de conceber a relação com a escola tendem a se revelar na finalidade que se atribui à escolarização. Segundo Charlot (1996), o saber implica uma atribuição de sentido ao próprio fato de ir à escola e aprender coisas. 0 autor revela que, para alguns, "é preciso ir à escola 'o maior tempo possível', para mais tarde ter uma 'boa profissão', portanto, um 'bom futuro', uma 'bela vida' - ou ainda: uma vida normal” (CHARLOT, 1996, p. 55).

A pesquisa apreendeu que as principais razões para cursar o ensino médio, entre os jovens da amostra, estão relacionadas, sobretudo, às expectativas futuras ligadas ao trabalho, indicando ser esta uma questão importante. Mais de $82,99 \%$ dos estudantes acreditam que conseguirão um bom trabalho após concluir o ensino médio - dessa vez, sem diferenças tão substanciais entre integral $(84,95 \%)$ e parcial $(80,86)^{18}$. Cerca de $40 \%$ dos jovens expressaram que o ensino médio está sendo cursado "para conseguir melhor trabalho"

${ }_{17}$ Vale destacar que, neste item, foram anuladas $46,15 \%$ e $44,8 \%$ das respostas do período integral de dois estados: São Paulo e Ceará, respectivamente. A comanda era para a escolha de somente uma opção e as respostas foram anuladas por conta de questionários com mais de uma alternativa assinalada.

18 Nesse item aparecia a frase "após concluir o ensino médio, conseguirei um bom trabalho", com a qual o estudante poderia concordar ou discordar (totalmente e parcialmente), além de não responder. 
- 39,2\% entre os jovens do período integral e $42,9 \%$ do parcial $^{19}$. Chama a atenção, ainda, que entre os do integral, há uma maior frequência $(20,74 \%)$, ainda que discreta, de um sentido para a escolarização como uma "finalidade sem fim" do que no parcial (17,98\%): trata-se daqueles que estudam porque "gostam de estudar", que entendem os estudos como um fim em si mesmo e desprovido de um objetivo prático. Há, além disso, os que assinalaram, no mesmo item, a alternativa de querer continuar os estudos $(22,12 \%$ para 0 conjunto da amostra, sendo $19,6 \%$ os alunos do período integral, e $24,92 \%$ os do parcial). 0 fato, a princípio contraintuitivo, de um percentual maior de alunos do parcial ter escolhido essa alternativa (a despeito do menor percentual entre os alunos do integral) nos lembra, porém, que continuar os estudos, além de sinalizar uma possível ampliação de ambições escolares/ acadêmicas, também é relevante, em um contexto de alongamento do tempo de escolarização, para conseguir melhores oportunidades de trabalho.

A certeza da continuidade dos estudos, no entanto, não é absoluta entre os jovens. Ao ser interpelados pela afirmação "Eu acredito que os alunos desta escola vão continuar seus estudos quando concluírem o ensino médio", que demanda um olhar relacional, não apenas atentando para os próprios desejos e possibilidades, mas também para as possibilidades dos seus pares, vemos a falta de clareza, por parte dos jovens, nas reais chances de isso ocorrer: se $61,58 \%$ da amostra concordou com tal afirmativa, a diferença da crença entre alunos do integral $(71,59 \%)$ e do parcial $(50,47 \%)$, mais uma vez, demonstra o papel central das condições escolares na conformação das relações com a escola e com a própria experiência escolar, e parece se manifestar, também, na ambiguidade no que se refere às pretensões ou expectativas, de um lado, e probabilidades efetivas, de outro.

Juntando isso ao fato de que $15,25 \%$ dos alunos da amostra relataram que já trabalham - porém, e mais uma vez, com grande discrepância entre alunos do parcial $(23,97 \%)$ e integral $(7,39 \%)$, sendo três vezes superior 0 percentual de estudantes trabalhadores do EM no período parcial -, vemos que os estudantes atendidos em período integral, mesmo em territórios mais vulneráveis, onde muitos precisam contribuir com a renda familiar, parecem ter mais possibilidades de gozar da condição de estudante - a própria operacionalização do regime integral, ao que tudo indica, dificulta ou impede a concomitância do exercício de atividades remuneradas.

19 Na pergunta “Por que você está cursando o ensino médio?", 14,05\% das respostas foram anuladas em razão de haver questionários com mais de uma alternativa assinalada, quando a comanda do item era para a escolha de somente uma opção. 
A pesquisa realizada teve como objetivo discutir as relações de jovens com a escola e com o saber, bem como examinar como essas relações se diferenciam de acordo com a experiência de se estudar em unidades de tempo integral e parcial. A apreensão dessas relações pode trazer contribuições para o aprimoramento de políticas públicas educacionais voltadas para o ensino médio concatenadas com os anseios desse grupo geracional e compromissadas com o combate às desigualdades escolares e sociais.

A pesquisa com os jovens reiterou - como outros artigos deste número da Cadernos Cenpec - que a oferta concomitante do ensino médio em período integral e parcial criou condições desiguais de atendimento. Diferenças de perfil entre os alunos dos regimes parcial e integral aparecem de modo relevante. Além disso, a composição do alunado dessas unidades tende a não refletir exatamente o perfil de seu entorno e muitos estudantes são provenientes de outros bairros e até de outros municípios, o que sugere uma concorrência entre famílias por vagas nessas escolas, geralmente mais prestigiadas pela comunidade, tal como revela sua avaliação pelos alunos. É possível também levantar a hipótese - demonstrada por trabalho de pesquisa realizado pelo Tribunal de Contas do Estado de São Paulo (TCE, 2016), abordado em Batista et al. (2016) - de que muitos jovens do entorno vulnerável abandonem as escolas de tempo integral por não se adequarem a elas em razão de seu menor capital cultural herdado.

A pesquisa mostrou, ainda, que a sociabilidade com os colegas é aquilo de que os alunos do ensino médio mais gostam na escola. A literatura aponta que essas relações de convívio entre pares influencia a avaliação e até a permanência na escola, dado que pode ser confirmado no alto grau de aprovação da unidade escolar, indicado pelo fato de que quase $80 \%$ dos alunos afirmaram gostar da escola em que estudam. Os laços afetivos ali construídos, muitas vezes, perduram nas relações sociais extraescolares e, em territórios vulneráveis, essa sociabilidade tende a ganhar maior dimensão à medida que a ausência de equipamentos públicos e de lazer nos bairros desloca para a escola muitas das expectativas de produção de sociabilidades juvenis. Entendendo a importância das relações de convívio entre os jovens, a pesquisa identificou que grande parte da amostra participa de grupos religiosos, o que, especialmente em meios vulneráveis, ganha destaque por significar o pertencimento a um grupo, que permite a construção de uma identidade e de uma rede de apoio e de sustentação, ansiada pelos jovens 
de meios vulneráveis, mesmo que, sob um ponto de vista externo, possa significar a submissão a uma estrita ordem moral. Surpreendentemente, os grêmios estudantis foram indicados por apenas $6,88 \%$ dos alunos, sugerindo a necessidade de se discutir essa instância de participação. A despolitização dos grêmios pode ter aberto caminho para outras formas de organização juvenil mais críticas, como as ocupações, os coletivos, entre outros, e pode explicar o pouco interesse em participar nesse canal.

Na relação com o saber, os estudantes da amostra atribuem sentido ao ensino médio: a escola parece ser vista, especialmente, como porta de entrada para melhores oportunidades de trabalho. Para $82,99 \%$ dos jovens, a conclusão dessa etapa aumenta a possibilidade de conseguir um bom trabalho, com leve diferença entre os jovens atendidos em regime parcial (42,90\%) e no integral $(39,20 \%)$. Como relatado, chama a atenção, no entanto, a maior frequência (20,74\%), ainda que discreta, entre os alunos do período integral, de um sentido para a escolarização como uma "finalidade sem fim" (versus 17,98\% no parcial): seriam aqueles que estudam porque "gostam de estudar", cuja relação com o saber se dá, sobretudo, como um fim em si mesmo, a despeito de um objetivo prático, mais diretamente vislumbrado. Complementarmente, $22,12 \%$ dos estudantes relataram querer continuar os estudos $(19,6 \%$ do período integral, e $24,92 \%$ do parcial), nos relembrando tanto da importância disso, em um contexto de ampliação do tempo de escolarização, para conseguir melhores oportunidades de trabalho, bem como sinalizando, talvez, outras aspirações de seguir estudando ou acumulando qualificações antes de entrar, mais efetivamente, no mundo do trabalho.

Porém, a falta de clareza nas reais possibilidades de que esse empreendimento seja bem-sucedido traz à tona, novamente, as ambuiguidades e os dilemas dos estudantes dos territórios mais vulneráveis, mas sobretudo para o modo como as condições escolares - e a diferenciação das oportunidades educacionais afetam as relações com a escola e com a própria experiência escolar também nesse contexto: se apenas $61,58 \%$ dos jovens vislumbram que os alunos da escola em que estudam continuarão seus estudos quando concluírem o ensino médio, mais uma vez é importante a diferença de perspectiva entre estudantes do integral (71,59\%) e do parcial (50,47\%).

Se, por um lado, como apontam estudos recentes, é preciso atentar para as diferentes experiências juvenis, que se distinguem não apenas conforme questões individuais, mas que estão relacionadas a determinantes econômicos, sociais, culturais, étnico-raciais, de gênero etc., a diversificação 
da oferta do ensino médio e seus riscos na acentuação às desigualdades, mais uma vez, é reacendida na comparação das expectativas dos alunos do tempo integral e do parcial.

Vale ressaltar, por fim, que o novo estatuto obrigatório do ensino médio reforça a necessidade de o Estado assegurar, por meio de políticas públicas, não apenas o direito dos jovens ao acesso a essa etapa de ensino, mas, e em especial no caso de territórios mais vulneráveis, promover políticas públicas que garantam a sua permanência, com a adequada qualidade, combatendo as desigualdades e os históricos e estruturais problemas e desafios encontrados na educação brasileira. Do contrário, como já analisaram Bourdieu e Champagne (1998, 2008), no caso da universalização do acesso ao segundo grau na França, corre-se o risco de ter, também no processo brasileiro, "excluídos do interior" ${ }^{20}$, isto é, estudantes "marginalizados por dentro" do sistema escolar.

20 Bourdieu e Champagne (2008), em análise das transformações do sistema de ensino francês desde os anos 1950 (que envolveu o prolongamento da obrigação escolar até os 16 anos e a consequente ampliação do acesso de categorias sociais até então excluídas ao ensino secundário), relatam que, nesse processo, houve multiplicação, nos seus termos, dos "excluídos do interior", isto é, estudantes "marginalizados por dentro" do sistema escolar por meio de "práticas de exclusão brandas, ou melhor, imperceptíveis, no duplo sentido de contínuas, graduais, e sutis, insensíveis” (p. 483), por parte de quem as exerce e também de suas vítimas. 0 processo de exclusão teria sido adiado e diluído no tempo, mas seguia ocorrendo na escola. A instituição escolar estaria habitada por excluídos potenciais, "vivendo as contradições associadas a uma escolaridade sem outra finalidade que ela mesma” (p. 483). Portadores de diplomas muito desvalorizados, estudantes (e suas famílias) começam a perceber que o acesso ao secundário não garantiria ter sucesso nele, e que ter sucesso nos estudos não garantiria acesso às posições sociais (como quem fazia o secundário antes, na sua época mais elitista). Para os autores, a instituição escolar começa a ser percebida gradativamente "como um engodo e fonte de uma imensa decepção coletiva: uma espécie de terra prometida, sempre igual no horizonte, que recua à medida que nos aproximamos dela” (p. 483). 


\section{Youths and secondary education: students' relationship with school and with knowledge in social vulnerability areas}

Abstract: The goal of this article is to provide a better comprehension of the problems youths have been faced with in their relationship with school and with knowledge in vulnerable areas. The matter under analysis is a survey applied to 669 students in the second grade of secondary education in 24 state schools situated in 17 municipalities in the Brazilian states of Ceará, Goiás, Pernambuco and São Paulo. The research identifies in the students responses differences both of profile between those attending part-time and full-school and of how they face the job market and the continuity of their education. Finally, it calls attention to the problematic of the diversification of secondary education's offers and how it may increase inequality, the latter being a question that arises if we compare the expectation of part-time and full school students.

Keywords: Secondary education. Youths. School. Vulnerable areas. 


\section{Juventud(es) y enseñanza media: relación de los estudiantes con la escuela y con el saber en territorios de vulnerabilidad social}

Resumen: El objetivo de este artículo es contribuir a una mayor comprensión y también al enfrentamiento de los problemas y desafíos encontrados por los jóvenes en su relación con la escuela y con el saber, en particular en territorios más vulnerables. Se partió de cuestionarios aplicados a 669 estudiantes del segundo año de la enseñanza media de 24 escuelas estatales ubicadas en 17 municipios de los estados brasileños de Ceará, Goiás, Pernambuco y São Paulo. La investigación identificó diferencias entre el perfil de los alumnos de los períodos parcial y completo y la manera que las condiciones escolares - y la diferencia entre la oferta de oportunidades educacionales - pueden afectar e influenciar la relación de los jóvenes con la propia escuela y con el saber, así como en el modo como los jóvenes comprenden su entrada al mundo del trabajo y la continuidad de sus estudios. Por fin, la investigación discute el problema de la diversidad en la oferta de plazas en la enseñanza media y el riesgo de aumentarse la desigualdad, problemática que se pone en evidencia al compararse las expectativas de los estudiantes que están en la escuela en tiempo integral o parcial.

Palabras clave: Enseñanza media. Juventud(es). Escuela. Territorio vulnerable. 


\section{REFERÊNCIAS}

ABRAMOVAY, M.; CASTRO, M. G.; WAISELFISZ, J. J. Juventudes na escola, sentidos e buscas: por que frequentam? Brasília: Flacso - Brasil, OEI, MEC, 2015.

BATISTA, A. A. G. et al. Políticas para o ensino médio: o caso de quatro estados. Cadernos Cenpec, São Paulo, v. 6, n. 2, 2016.

BAUDELOT, C.; ESTABLET, R. L’École capitaliste en France. Paris: Maspero, 1971.

BOURDIEU, P. La distinction. Paris: Minuit, 1979.

BOURDIEU, P. Futuro de classe e causalidade do provável. In: NOGUEIRA, M. A.; CATANI, A. (Org.). Escritos de educação. Petrópolis: Vozes, 1998.

; PASSERON, J. C. La reproduction. Paris: Minuit, 1970.

; CHAMPAGNE, P. Os excluídos do interior. In: NOGUEIRA, M. A; CATANI, A. (Org.). Escritos da educação. Petrópolis: Vozes, 1998.

; ______. Os excluídos do interior. In: BOURDIEU, P. (Org.). A miséria do mundo. Petrópolis: Vozes, 2008.

BOWLES, S.; GINTIS, H. Schooling in capitalist America. Nova York: Basic Books, 1976.

BRASIL. Constituição Federal (1988). Emenda Constitucional no 59, de 11 de novembro de 2009. Diário Oficial da União, Seção 1, de 12 de novembro de 2009.

CARRANO, P. C. R.; MARTINS, C. H. dos S. A escola diante das culturas juvenis: reconhecer para dialogar. Educação (UFSM), v. 36, p. 23-56, 2011.

CASTRO, A.; LOPES, R. E. A escola de tempo integral: desafios e possibilidades. Ensaio: aval. pol. públ. educ., Rio de Janeiro, v. 19, n. 71, p. 259-282, abr./jun. 2011.

CHARLOT, B. (Org.). Os jovens e o saber: perspectivas mundiais. Porto Alegre: Artmed, 2001. - Relação com o saber e com a escola entre estudantes de periferia. Cadernos de Pesquisa, n. 97, p. 47-63, mai. 1996. 
DAYRELL, J. A escola “faz" as juventudes? Reflexões em torno da socialização juvenil. Educação e sociedade, Campinas, v. 28, n. 100, p. 1105-1128, out. 2007.

; CARRANO, P. O estado da arte sobre juventude na pós-graduação brasileira: educação, ciências sociais e serviço social (1999-2006). In: SPOSITO, Marília Pontes (Coord.). O estado da arte sobre juventude na pósgraduação brasileira: educação, ciências sociais e serviço social (1999-2006). Belo Horizonte: Argvmentvm, 2009.

; CARRANO, P.; MAIA, C. L (Org.). Juventude e ensino médio: sujeitos e currículos em diálogo. Belo Horizonte: Editora UFMG, 2014.

FERREIRA, S. G.; VELOSO, F. A. Mobilidade intergeracional de educação no Brasil. Pesquisa e Planejamento Econômico (PPE), v. 33, n. 3, p. 481-513, dez. 2003.

GOMES, E. E. No bairro tem igreja: práticas culturais entre jovens pentecostais. Cadernos CERU, [s.l.], n. 18, p. 69-89 , jan. 2007. Disponível em: 〈http://www. periodicos.usp.br/ceru/article/view/11833〉. Acesso em: 15 maio 2017.

INSTITUTO NACIONAL DE ESTUDOS E PESQUISAS EDUCACIONAIS ANÍSIO TEIXEIRA (INEP). Indicadores educacionais: Índice de Desenvolvimento da Educação Básica (Ideb) 2005 a 2015. Brasília: Inep, 2017.

. Sinopse estatística da educação básica: Censo Escolar 2015. Brasília: Inep, 2017.

KRAWCZYK, N. Reflexão sobre alguns desafios do ensino médio no Brasil hoje. Cadernos de Pesquisa, v. 41, n. 144, set./dez. 2011.

LEÃO, G.; DAYRELL, J. T.; REIS, J. B. dos. Jovens olhares sobre a escola do ensino médio. Cad. Cedes, Campinas, v. 31, n. 84, p. 253-273, maio-ago. 2011.

PEREIRA, A. B. Escritas dissonantes: escolarização, letramentos, novas tecnologias e práticas culturais juvenis. Horizontes Antropológicos, Porto Alegre, ano 21, n. 44, p. 81-107, jul./dez. 2015.

. 'A maior zoeira' na escola: experiências juvenis na periferia de São Paulo. 1. ed. São Paulo: Editora da Unifesp, 2016. v. 1, 240 p.

ROSENTHAL, R.; JACOBSON, L. Pygmalion in the classroom (Expanded ed.). Nova York: Irvington, 1992. 
SCOTT, R. P.; CANTARELLI, J. Jovens, religiosidade e aquisição de conhecimentos e habilidades entre camadas populares. Caderno CRH, Salvador, v. 17, n. 42, p. 375-388, set./dez. 2004.

SPOSITO, M. P. (Coord.). O estado da arte sobre juventude na pós-graduação brasileira: educação, ciências sociais e serviço social (1999-2006). Belo Horizonte: Argvmentvm, 2009. v. 1 e 2. - Indagações sobre juventude e escola no Brasil. Jovenes Revista de Estudios sobre juventud, México, v. 22, p. 246-297, 2005.

- Juventude e educação: interações entre educação escolar e a educação não-formal. Educação e Realidade, v. 33, p. 83-97, 2008.

; SOUZA, R. Desafios da reflexão sociológica para análise do ensino médio no Brasil. In: KRAWCZYK, N. (Org.). Sociologia do ensino médio: crítica ao economicismo na política educacional. São Paulo: Cortez Editora, 2014. v. 1, p. 33-62.

SOARES NETO, J. J. et al. Uma escala para medir a infraestrutura escolar. Est. Aval. Educ., São Paulo, v. 24, n. 54, p. 78-99, jan./abr. 2013.

TRIBUNAL DE CONTAS DO ESTADO DE SÃO PAULO (TCE-SP). Relatório de fiscalização de natureza operacional sobre os modelos de educação em período integral existentes na Rede Pública Estadual de Ensino. São Paulo, 2016.

VIÉGAS, L. de S.; SOUZA, M. P. R. de. A progressão continuada no estado de São Paulo: considerações a partir da perspectiva de educadores. Revista Semestral da Associação Brasileira de Psicologia Escolar e Educacional (Abrapee), v. 10, n. 2, p. 247-262, jul./dez. 2006.

VIEIRA, S. L. et al. Reações das políticas educacionais estaduais nas escolas: um estudo de caso em escolas do Ceará, Goiás, Pernambuco e São Paulo. Cadernos Cenpec, São Paulo, v. 6, n. 2, 2016.

VOLPI, M.; SILVA, M. S. S.; RIBEIRO, J. 10 desafios do ensino médio no Brasil: para garantir o direito de aprender de adolescentes de 15 a 17 anos. 1. ed. Brasília: Unicef, 2014. 
Sobre os autores:

Pâmela Félix Freitas é doutoranda em Educação pela USP, mestre em Educação pela mesma instituição e pesquisadora do Cenpec.

E-mail: pamela.freitas@cenpec.org.br

Antônio Augusto Gomes Batista é doutor em Educação pela Universidade Federal de Minas Gerais e coordenador de Desenvolvimento de Pesquisas do Cenpec.

E-mail: antonio.batista@cenpec.org.br

Hivy Damasio Araújo Mello é doutora em Sociologia pela Universidade Estadual de Campinas (Unicamp) e líder de projetos de pesquisa do Cenpec.

E-mail: hivy.mello@cenpec.org.br

Recebido em: maio de 2017

Aprovado em: junho de 2017 